\title{
Dicionário histórico do português do Brasil: um modelo de dicionário histórico
}

\author{
Clotilde de Almeida Azevedo Murakawa*
}

RESUMO: Este artigo apresenta o percurso teórico e metodológico empregado para a construção do Dicionário Histórico do Português do Brasil - séculos XVI, XVII e XVIII (CNPq/ $\mathrm{MCT}$ ). Partindo de alguns tipos e modelos descritos por lexicógrafos sobre dicionários históricos ou diacrônicos, estabelece-se o modelo que estrutura o Dicionário Histórico que tem por objetivo reunir em uma obra de consulta o léxico da língua portuguesa que, nos séculos XVI, XVII e XVIII, fixou um repertório lexical que veio a constituir o português do Brasil. A base de referência é um banco de dados constituído de documentos dos mais variados gêneros dos três séculos da história colonial brasileira. Este banco de dados além de fornecer a nomenclatura do dicionário histórico, permite que, através das unidades lexicais contextualizadas, possa ser construída a definição lexicográfica, acompanhada de exemplos abonados.

Palavras-chave: Lexicografia; dicionário histórico; verbete; definição.

ABSTRACT: This article presents the theoretical and methodological road used to construct the Historical Dictionary of Brazilian Portuguese in the XVI, XVII and XVIII centuries $(\mathrm{CNPq} / \mathrm{MCT})$. Starting with some examples and models of historical and diachronic dictionaries we set the model that structures the Dictionary; it has the purpose of assembling in a single book the portuguese language lexicon responsible for the construction of the portuguese language in Brazil. Our reference basis is a data bank with many sorts of sources existing along the three centuries of the Brazilian colonial history. This data bank provides the nomenclature of the historical dictionary and allows the construction of the lexicographical definition through its lexical context that is followed by consecrated examples.

Keywords: Lexicography; historical dictionary; main entry; definition.

\footnotetext{
UNESP - Universidade Estadual Paulista / CNPq - e-mail: jtm.jau@uol.com.br.
} 
1. Introdução

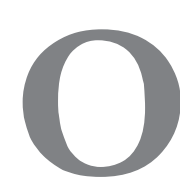

Projeto Dicionário Histórico do Português do Brasil - séculos XVI, XVII e XVIII (DHPB), (Programa Instituto do Milênio - CNPq) teve a sua estrutura idealizada e construída por Maria Tereza Biderman. Já em 1984, Biderman, em artigo publicado na Revista Alfa (1984), intitulado a "Ciência da Lexicografia", ao tratar da tipologia dos dicionários menciona vários modelos de dicionários históricos e enfatiza o modelo que tem por base a língua de uma determinada época, como o de Godefroy de 1881, sobre a língua francesa e seus dialetos no período que vai do século IX ao XV. Ainda no mesmo artigo Biderman (1984: 13) menciona o histórico pancrônico, mais conhecido como etimológico que, a partir da perspectiva da língua contemporânea, vai se ocupar dos estágios anteriores de uma língua remontando às suas origens. Foi pensando no modelo de dicionário histórico que reúne a língua de um determinado período que Biderman construiu a estrutura do DHPB.

\section{Conceito e Modelos de Dicionários Históricos}

Para se estabelecer o modelo adotado para o Dicionário Histórico em questão - DHPB - necessário se faz percorrer algumas obras de lexicógrafos que trataram do assunto, ou melhor dizendo, que definiram o que é um dicionário histórico e seus diferentes modelos

Dubois e Dubois (1971) ao traçarem a relação entre história e dicionário afirmam que a descrição histórica de uma língua só pode ser feita através de uma metalíngua; faz-se uma descrição sincrônica de uma evolução diacrônica. Para os autores, os verdadeiros dicionários históricos são aqueles que definem um estado de língua correspondendo a um funcionamento historicamente definido e a metalíngua empregada só pode ser feita com palavras atuais. Dentro desta perspectiva é que foi construído o projeto do Trésor de la Langue Française.

Buscando em Imbs (1960: 8) amparo teórico, dizem os autores que para cada período de língua não apenas os sentidos novos devem ser buscados, mas também os antigos que subsistem ao lado dos novos; e é sobre esta base antiga que a novidade tem o seu relevo. O conteúdo semântico de cada palavra sente os efeitos do seu percurso ao longo do tempo e do espaço.

Em realidade, são enunciados produzidos num determinado tempo e espaço que vêm carregados de história e não as palavras isoladamente. Dubois e Dubois (1971) ressaltam, ainda, o valor dos documentos para a construção de um dicionário histórico. 
Em La tipologia de las obras lexicográficas Haensch (1982: 102) define o dicionário histórico como sendo um "[...] dicionário semasiológico que descreve as fases anteriores de evolução de sistemas linguísticos coletivos." 1

A finalidade do dicionário histórico é registrar a evolução que as palavras sofrem ao longo dos séculos, utilizando os textos com suas datas correspondentes, indicando grafias diferentes e as variações semânticas e morfológicas encontradas. O dicionário histórico é para Haensch uma obra documentada, ou seja, a contextualização da palavra-entrada e sua datação são os elementos mais importantes. Difere do etimológico que se ocupa da origem das palavras e de sua suposta pré-história. Ambos os dicionários são construídos numa perspectiva temporal.

Com a denominação de dicionários diacrônicos, Porto-Dapena (2002: 51) distingue dois tipos fundamentais: o histórico e o etimológico. O histórico deve se ocupar da história das palavras desde o primeiro momento em que aparecem na língua até o momento atual ou de seu desaparecimento. Já o etimológico deve se ocupar da origem das palavras, ou como ele a denomina, "sua pré-história"

Para o lexicógrafo espanhol, o dicionário histórico em seu sentido estrito deve apresentar algumas características específicas: 1) ser geral e exaustivo e não apresentar nenhum tipo de restrição em sua microestrutura, representada por todas as palavras pertencentes às diferentes épocas de uma língua; por esta razão deve estar baseado em textos que autorizem ou testemunhem a existência delas em largo período de tempo; 2) ter sua atenção voltada para a datação, ou seja, quando apareceu pela $1^{a}$ vez na língua; 3) construir o processo evolutivo das palavras, submetendo as diferentes acepções a uma ordenação histórica ou histórico-genética.

Ainda no eixo temporal de construção de dicionários, Campos Souto e Perez Pascual (2003) classificam o dicionário histórico no quadro dos dicionários diacrônicos que têm por objetivo examinar a evolução histórica do léxico de uma determinada língua. Estas obras diacrônicas, segundo os autores são representadas pelos dicionários: tesouros ou thesauri, históricos, etimológicos e cronológicos. No caso específico dos históricos, objeto de interesse para este trabalho, são eles os que registram as mudanças que ao longo do tempo "[...] experimentam as palavras com o apoio em uma rica

"[...] diccionario histórico es uno diccionario semasiológico que describe las fases anteriores de evolución de sistemas lingüísticos colectivos. (Haensch, 1982: 102, tradução nossa). 
documentação textual; são eles dicionários de língua com um método histórico." (Campos Souto; Perez Pascual, 2003: 63, tradução nossa)².

Os dicionários históricos podem ser construídos com base em quatro modelos diferentes: 1) dicionário histórico de evolução semântica, que registra as mudanças de significação que as unidades sofrem em seu percurso histórico; 2) dicionário sincrônico-diacrônico, que busca dividir a história do léxico em períodos cronológicos concretos, e o léxico é objeto de estudos autônomos; 3) dicionário histórico documental, que não se preocupa com a evolução semântica, mas limita-se a documentar historicamente e sem cortes as acepções das palavras (Porto-Dapena, 2002); e um quarto e último tipo, coordena o diacrônico com um critério normativo que separa em período "áureo" de uma língua e em períodos que antecedem ou seguem este período; neste modelo a evolução histórica sofre cortes, mas no interior do artigo lexicográfico, e adquire um caráter normativo, como é o caso do Dictionnaire de la langue française (1875-1877) de Émile Littré, que registra a etimologia e em notas acrescenta os dados normativos da palavra, seguido do contexto ou dos contextos nos séculos em questão.

Diante das considerações sobre conceitos e modelos que orientam a elaboração de dicionários históricos, podemos definir o Dicionário Histórico do Português do Brasil como um dicionário que registra as mudanças que as palavras sofrem no decorrer do tempo com o apoio de uma vasta documentação textual referente a três séculos de história do Brasil Colônia. É, portanto, um dicionário documental, de acordo com a classificação de Porto-Dapena (2002) que faz um recorte sincrônico do passado. Tem, entretanto, objetivos específicos: 1) reunir numa obra de consulta o léxico da língua portuguesa que, no período do Brasil Colonial, fixou um repertório lexical que veio a constituir o português brasileiro; 2) registrar as unidades lexicais substantivos, adjetivos e verbos que compõem a nomenclatura do Dicionário Histórico; 3) extrair dos contextos, inseridos no banco de dados, todas as acepções que a palavra-entrada ou lema possui, acompanhadas do contexto e de completa informação bibliográfica; 4) registrar a data mais antiga que a entrada apresenta no conjunto de todos os documentos que compõem o banco de dados.

“[...] experimentan las palabras, con apoyo en una rica documentación textual; son diccionarios de lengua con un método histórico. (Campos Souto; Perez Pascual, 2003: 63). 
2. A construção do corpus

Utilizando dois programas que permitem a busca de unidades lexicais em seus contextos como o Pbilologic e o UNITEX 2.0, o banco de textos do DHPB foi construído estabelecendo o ano de 1500 e a Carta de Pero Vaz de Caminha como ponto de partida para a seleção de documentos que foram inseridos no banco, abrangendo três séculos do Brasil Colônia. E considerou-se o ano de 1808, quando da vinda da família real portuguesa para o Brasil, a data-limite para a seleção dos textos/documentos.

$\mathrm{O}$ tratamento computacional dado às obras impressas foi o seguinte:

A) Fase executada por especialista em scanner:

1) Escaneamento dos textos selecionados;

2) Captura das imagens após escaneamento;

3) Limpeza das imagens para a retirada de marcas, riscos e borrões que podem dificultar a leitura do texto posteriormente.

B) Fase de correção e revisão dos textos escaneados:

1) Transformação dos textos com extensão TIF para Doc.;

2) Correção dos textos com preservação da escrita original através do programa ABBYY;

3) Armazenamento dos textos em formato Doc., já corrigidos.

No caso das obras já digitalizadas apenas fez-se a transformação do texto com extensão TIF para Doc., enviando-o, posteriormente, para o armazenamento.

Todas essas fases foram elaboradas no Laboratório de Lexicografia, sede do projeto do DHPB, na Faculdade de Ciências e Letras da UNESP de Araraquara.

Terminadas as fases, os textos em formato Doc. foram enviados ao Instituto de Ciências Matemáticas e da Computação na Universidade de São Paulo, em São Carlos, para a composição do banco de dados. É relevante evidenciar que todos os textos escaneados foram guardados em um banco de textos originais que permitem esclarecer qualquer dúvida com relação aos textos do corpus.

Buscou-se, na medida do possível, selecionar as obras em sua $1^{a}$ edição, ou então, em edições cujos editores deram um tratamento confiável a elas. Com relação aos textos manuscritos que também integram o banco de dados, a seleção recaiu sobre os trabalhos de transcrição que obedeceram a 
critérios filológicos. Também integram o banco textos digitalizados que sofreram tratamento computacional adequado para sua inserção.

Com relação à tipologia das obras escolhidas, há que se ressaltar que, tendo em vista os objetivos específicos do DHPB, elas foram as mais variadas possíveis: obras dos missionários viajantes, na sua maioria jesuítas que vieram em missão catequética e no Brasil se fixaram; diários de navegação, como o de Pero Lopes de Sousa, irmão de Martim Afonso de Sousa; cartas de sesmarias; roteiros descritivos da flora e fauna brasileiras; descrições geográficas; cartas e sermões do Pe.Vieira, pregados aqui no Brasil e de outros oradores sacros, que para aqui vieram; obras e documentos que tratam do Estado do Grão Pará, durante a era pombalina; obras sobre a nobiliarquia paulistana; atos de câmaras municipais; documentos cartoriais; autos de devassas feitos durante a Inconfidência Mineira; processos; inventários; testamentos; alvarás; posturas; bandos; atos de doações de terras, casas e terrenos; cartas de ofício; patentes; cartas dos governadores gerais; provisões; documentos forenses; constituições dos bispados no Brasil; regimentos militares; obras sobre medicina, farmácia, agricultura, etc., e muitas outras, num conjunto que pode ser considerado "monumental" para os fins a que foi proposto.

Para cada texto inserido no banco, foi elaborada uma ficha catalográfica, onde estão registradas todas as informações possíveis sobre a obra, seu autor, data em que foi produzida, data da edição utilizada, editor, editora, local e data da edição, volume, biblioteca onde a obra foi localizada, além de informações sobre a biografia do autor, quando possível, e sobre a obra em si, ou seja, suas partes e informações contidas em notas prévias ou introdutórias.

Dos três séculos do período colonial no Brasil, foram escolhidos textos, alguns deles inéditos, pois são manuscritos localizados em arquivos e museus em cidades de Minas Gerais e que sofreram processo de transcrição. Outros, já digitalizados, pertencentes à Biblioteca Pública de Évora, em Portugal, como é o caso de Cultura e Opulência do Brasil, por suas drogas e minas, de autoria de André João Antonil, cuja publicação em 1711 foi confiscada por ordem do Rei D. João V, restando pouquíssimos exemplares em bibliotecas internacionais. A Biblioteca Pública de Évora é a guardiã de um dos exemplares que escaparam ao confisco real.

As obras literárias do período do barroco e do arcadismo brasileiros também foram contempladas na seleção.

Contando com aproximadamente 7 milhões e 500 mil ocorrências, está construído o corpus que permite aos redatores extraírem as unidades lexicais para a redação dos verbetes. Há, entretanto, a necessidade de se cons- 
truir um outro banco para que o Dicionário Histórico possa ser aperfeiçoado num futuro próximo com documentos, principalmente, dos séculos XVI e XVII.

\section{A construção do verbete}

“Todo dicionário [...] consiste num estudo atomístico do léxico na medida em que considera isoladamente as palavras que servem de entradas"', diz Porto-Dapena (2002: 182). É a partir da palavra-entrada ou lema que se organiza o verbete ou artigo lexicográfico que oferece uma série de informações sobre a unidade lexical em estudo, informações que se referem a múltiplos aspectos, mas que têm sua prioridade no aspecto semântico. Desta forma, pode se dizer como Dubois e Dubois (1971: 84), que o verbete de um dicionário é um enunciado que tem como sujeito a palavra-entrada e como predicado a definição. Esta, por sua vez, é o centro de todo o artigo lexicográfico.

No caso do DHPB, as definições são construídas a partir dos contextos localizados através de motores de busca no corpus. Não se pode descartar, entretanto, o auxílio de obras de referência da língua portuguesa que podem orientar a definição, principalmente, as que foram publicadas nos séculos XVIII e XIX, como as de: Bluteau (1712-1728), Silva (1789 e 1813), Vieira (1871-1874), Pinto (1836), Caldas Aulete (1881). Do século XX e XXI, Figueiredo (1925), Freire (1939-1843), Nascentes (1961-1967), Ferreira (2001), Houaiss e Villar (2001) E também dicionários etimológicos como os de Nascentes (1932), Machado, Moreno e Cardoso Jr. (1967) e Cunha (1996). Informações também devem ser buscadas em enciclopédias e em obras, especialmente, aquelas sobre a História do Brasil Colônia.

O verbete no DHPB registra ao lado da entrada a sua classe gramatical. Se ela tiver mais de uma função gramatical de acordo com os contextos, uma outra entrada deverá ser inserida tendo um número alceado: escravo ${ }^{1}$ escravo $^{2}$; atrevido $^{1}-$ atrevido $^{2}$; sublime $^{1}-$ sublime $^{2}$.

A etapa seguinte registra as variantes que a unidade lexical entrada pode apresentar no banco de dados. Para a obtenção dessas variantes deve ser utilizada a busca por similaridades do programa Philologic que permite, até certo ponto, localizá-las. O redator deve, entretanto, "criar" outras possíveis

3 Todo diccionario “[...] consiste en un estudio atomístico del léxico en la medida en que considera aisladamente las palabras que le sirven de entradas." 
variantes de acordo com o conhecimento que tem da história da língua portuguesa e proceder nova busca. É o caso de entradas terminadas em ditongo -ão que podem aparecer grafadas -om, -am, -ã, ou ainda aõ, com o til no o. Este procedimento pode auxiliar a localização de outras variantes. Um tipo de variante bastante frequente é a gráfica. Uma entrada pode, às vezes, apresentar 8, 10 variantes ou mais, registradas em diferentes textos de diferentes épocas. É o caso de contradição que apresenta 13 variantes, ou ainda correição, com 18 variantes, todas elas gráficas. Faz-se a distribuição delas de acordo com as acepções registradas no banco de dados.

Registradas as variantes, registram-se os valores polissêmicos que a entrada pode ter em todo o conjunto de textos selecionados. Como já foi dito anteriormente, é o contexto que irá definir semanticamente o lema. Muitas vezes somente o contexto permite ao redator elaborar a definição; e esta, no caso de unidades lexicais substantivo é construída seguindo o clássico modelo aristotélico por meio do genus proximum e differentia specifica. Um verbete do DHPB terá tantas definições quantas forem as acepções encontradas nos contextos e estes completam a definição.

A este respeito Weinrich (1979: 329), em artigo intitulado A Verdade sobre os Dicionários, citando Jacob Grimm que afirma que "[...] as palavras exigem exemplos e os exemplos exigem autoridade, porque sem ela perderiam o melhor de sua força", se manifesta "[...] desejando para um dicionário moderno muitos exemplos, os mais numerosos possíveis, e que esses exemplos sejam expressivos e documentados com precisão com frases, ou melhor, com textos." E mais adiante conclui: "Não há, portanto, qualquer motivo, nem do ponto de vista prático, nem do ponto de vista teórico, para se desprezarem e muito menos se eliminarem os exemplos dos dicionários." (Weinrich, 1979: 330).

As palavras de Weinrich dão respaldo ao procedimento adotado no DHPB. Cada definição é acompanhada de um contexto documentado, e por isso autorizado, e também cada variante é submetida a este mesmo procedimento. Uma entrada como borboleta apresenta a variante braboleta; cereja - cereija; primeiro - primero e premeiro; pederneira - pedreneira e perdeneira; ouro - oro e oiro; terebentina - termentina, trementina e trebentina. São tipos diferentes de variantes e cada uma terá o contexto onde está inserida. Esta informação oferece ao consulente as possibilidades que a palavra-entrada apresenta em contextos e épocas diversas.

Definidas as acepções do lema, registra-se no interior do verbete a marca linguística figurado quando o contexto a evidencia. Uma acepção nunca pode ser chamada de figurada, diz Porto-Dapena (2002: 256, tradução nossa) 
[...] se ao seu lado num mesmo artigo lexicográfico não aparece a correspondente acepção não figurada, a qual, obviamente, seguindo uma ordem genética, deverá aparecer imediatamente antes. ${ }^{4}$.

Este é um tipo de registro que pode aparecer num dicionário histórico onde a evolução semântica pode ser demonstrada.

$\mathrm{Na}$ sequência da construção do verbete, são indicadas as expressões sintagmáticas, onde a unidade lexical de entrada é o centro da expressão; cada expressão sintagmática recebe também uma definição, como nos seguintes exemplos: Negro solto (Escravo alforriado); Rédea solta (Sem governo, sem orientação); Sono solto (profundo). E sob o rótulo locução, registram-se as locuções, como nos casos seguintes: De sabido ou de sabida (Conhecidamente); Ao parecer de (Com aparência de); A jeito (Em posição conveniente ou disposição propícia). Assim como as sintagmáticas, também são definidas.

Completa e encerra o artigo lexicográfico a datação. Segundo Matoré (1968: 23, tradução nossa)

As palavras não caem do céu, elas aparecem a sua hora, e a data de seu nascimento (que os linguistas chamam uma datação) é interessante na medida em que revela uma modificação na história de uma civilização ${ }^{5}$.

A datação, no caso específico do DHPB, indica o texto mais antigo do banco de dados que registra a unidade lexical de entrada e não a primeira vez em que ela apareceu na língua, informação de interesse exclusivo de dicionários etimológicos. A data em que o texto foi produzido pelo autor aparece ao lado da data da edição utilizada. Desta forma, a Carta de Pero Vaz de Caminha, 1500, é a mais antiga, e a limite é 1808. A unidade lexical caminho aparece na carta de Caminha de 1500; e o contexto seguinte que também a registra é de 1530, com o Diário de Navegação de Pero Lopes de Sousa, irmão de Martim Afonso de Sousa. Também estão em Caminha marinhajem, simgraduras, com a grafia original da carta em transcrição feita por Jaime Cortesão.

4 "Una acepción nunca podrá tacharse de figurada si a su lado, en el mismo artículo lexicográfico, no aparece a correspondiente acepción no figurada, la cual, obviamente, siguiendo una ordenación genérica, deberá aparecer imediatamente antes.”

5 Les mots ne tombent pas du ciel, ils apparaissent à leur heure, et la date de leur naissance (que les linguistes appellent une datation) est intéreesante dans la mesure où elle revele une modification dans l'histoire d'une civilisation. 
Em se tratando ainda da datação, pode ocorrer fato interessante, onde a data mais antiga no conjunto de documentos do banco de dados, esteja em sentido figurado; é o que acontece com a entrada academia. Depois da definição, registra-se a datação que está em sentido figurado em contexto de Ambrosio Fernandes Brandão:

- Local onde se ensina e se aprende.

Assim é, porque já vos disse que o Brasil era academia aonde se aprendia o bom falar, e isto baste por agora acêrca dos brancos, porque temos muito que dizer dos costumes do gentio da terra. AMBRÓSIO FERNANDES BRANDÃO (1966) [1618], DIÁLOGO SEXTO COSTUMES DOS NATURAIS [A00_1586 p. 192]. (1. a datação 1618).

A informação da data cumpre um dos objetivos específicos do DHPB que é reunir, desde 1500, ano da descoberta do Brasil, até 1808, o repertório lexical que deu origem ao português brasileiro.

Para a inserção de palavras homônimas - homófonas e homógrafas em entradas separadas e numeradas, adotou-se o procedimento clássico que vem orientando a técnica lexicográfica atual: critério diacrônico ou etimológico. Ou seja, unidades do léxico comprovadamente originárias de étimos diferentes onde a coincidência entre os significantes é resultado de evolução diacrônica, estão em entradas separadas, como nos clássicos exemplos de lima (instrumento para polir) e lima (fruto) nos contextos abaixo ${ }^{6}$ :

- O urucû nasce de arvores pequenas, o fructo he do tamanho, e feitio de huma lima mais pyramidal, tem huns grãos negros engastados em huma massa de escarlata [...].SEBASTIÃO DA ROCHA PITTA (1878) [1730], LIVRO PRIMEIRO. [A00_0567 p. 24].

- [...] sendo tãobem de ferro, gastão-se com mais presteza, e ficão mais perros; quando a superficie dos cilindros estiver ja brunida, esfregão-se com huma lima, para poderem engolir o algodao: [...]. MANUEL ARRUDA DA CAMARA (1799) [1797], CAPITULO X - DO DESCAROÇAMENTO, E ENSACCAMENTO. [A00_2260 p. 90].

Ou ainda num terceiro contexto em sentido figurado:

- O comer estaa já feito, hoc est: a doutrina e o necessario, que se pode pregar, passado huma e muytas vezes pola lima dos letrados de quá, porque

6 Os contextos foram retirados do banco de dados do DHPB, mantendo-se as numerações dos arquivos. 
sobre ysto se desvelou assás P. ^e Luis da Grãa [...]. P. ANTÓNIO PIRES (1956) [1560], CARTA DO P. ANTÓNIO PIRES AOS PADRES E IRMÃOS DE PORTUGAL, [ALDEIA DE SANTIAGO] BAÍA 22 DE OUTUBRO 1560. [A00_0046 p. 309].

No caso de homônimas em que uma das palavras tem o seu étimo duvidoso, não confirmado, foi feita a inserção em entradas separadas e numeradas, como acontece com a entrada gozo ${ }^{1}$ e gozo ${ }^{2}$ abaixo a seguir:

gozo $^{1}$ s.m.

Prazer, gosto, satisfação.

Olhay o grande gozo, \& doce gloria, Que tereis, quando pontos em dencanno, Contardes enta larga, \& trinte hintoria, junto do patrio lar, neguro, emenno. BENTO TEIXEIRA (1972) [1601], PROSOPOPEA. [A00_2570]. [A00_2570, p. 56].

gozo $^{2}$ s.m.

Cão pequeno e vulgar que tem as patas curtas

Criam-se nos rios de agua doce outros bichos, que se parecem com lontras de Portugal, a que o gentio chama jagoarapeba, que tem o cabello preto, e tão macio como velludo. São do tamanho de um gozo, tem a cabeça como de gato, e a boca muito rasgada e vermelha por dentro e nos dentes grandes prezas, as pernas curtas. GABRIEL SOARES DE SOUSA (1938) [1587], DOS MAMIFEROS TERRESTRES E AMPHIBIOS (PARTE SEGUNDA - TITULO 12). [A00_0188 p. 294].

Um outro aspecto a se destacar na construção do verbete ocorre quando a unidade lexical de entrada apresenta uma única acepção e em sentido figurado uma segunda acepção cujo significado denotativo não se encontra no banco de dados. Tal fato acontece, por exemplo, com a palavra banqueiro, cujo significado na quase totalidade dos contextos é: "Indivíduo que, durante a noite, fica encarregado da casa das caldeiras no engenho de açúcar", contextos de Antonil (1711) e de Frei Domingos do Loreto Couto (1757). Em sentido figurado, em trecho extraído de Vieira (1657), tem-se:

"Dizei-me: Se no monte da Piedade de Roma, ou no banco de Veneza se déra a cento por um, houvera quem alli não mettera o seu dinheiro? Pois os 
pobres são os banqueiros de Deus. Dá-se n'aquelle banco a cento por um, sendo nós tão amigos de acrescentar, não mettemos todo o nosso cabedal n'aquelle banco. Pois crêde-me que o banco de Veneza póde quebrar, como está hoje menos seguro com a guerra do turco, e o de Deus não ha-de quebrar, nem quebrou nunca. PADRE ANTONIO VIEIRA (1951) [1657], 3. SERMÃO DA QUARTA DOMINGA DA QUARESMA. [A00_0899 p. 74].

Este exemplo do Pe. Vieira representa a primeira datação da palavra no conjunto dos documentos. Depreende-se do contexto que os pobres são os intermediários, os negociadores de Deus. Curiosamente, a 9 edição do Diccionário da Língua Portugueza (s.d.) de António de Morais Silva, registra exatamente o mesmo exemplo e significado e a explicação de que "os pobres são banqueiros por quem as boas obras passão ao Céo", abonado o contexto por Duarte Nunes de Leão em sua obra Descrição de Portugal. A mesma citação se encontra em Domingos Vieira (1871) que registra ser "recolhido por Moraes" e em Machado (1967) que acrescenta o século XVI. A reprodução deste exemplo nos dicionários documenta e comprova que o saber lexical se transmite de uma obra lexicográfica a outra ao longo do tempo. Para um caso como este, orienta Porto-Dapena (2002, p. 256) que a acepção figurada deve aparecer sempre depois da não figurada. Mas adverte que o fato contrário é perfeitamente possível em um dicionário histórico, pois a evolução semântica pode ser demonstrada historicamente.

Selecionamos, a seguir, alguns verbetes construídos para o DHPB. Cada acepção vem acompanhada do exemplo abonado. A primeira datação, logo em seguida ao nome do autor, indica a edição que foi inserida no banco de dados; a segunda, marca a data ou o século em que o autor escreveu a obra; completa a informação o título da obra ou texto e a página, acompanhados da numeração dos arquivos no banco do DHPB.

\section{claridade s.f.}

variante: claridáde

1. Qualidade do que é claro, límpido.

[...] passeando defronte da caza do Cirurgião Mor Manoel Fernandes Nabuco, que fica na rua da Matris de São Pedro, e quasi fronteira a em que assiste o Senhor delle testemunha vio pela muita claridade da Lua, que na caza do 
dito Senhor [...]. desconhecido (1931) [1798], BAHIA -DEVASSAS E SEQUESTROS. [A00_2265 p. 113].

\section{Brilho luminoso.}

[...] quanto mais azeyte tiver a candeya, tanto mais tempo durará a luz della, e pelo contrario, quanto menos azeyte tiver, menos durará a nua claridade, e renplandor. LUIS GOMES FERREIRA (1735) [1735], DA CVRA DAS PONTADAS PLEURITICAS, E nUAS OBnERVAÇOENS. [B00_0029 p. 53].

3. Luz, iluminação.

[...] e as pombas e rolas são em tanta multidão que em certos campos muito dentro do sertão são tantas que quando se levantão empedem a claridade do sol, e fazem estrondo, como de hum trovão; [...]. PADRE FERNÃO CARDIM (1980) [1585], I - DO CLIMA E TERRA DO BRASIL - E DE ALGUMAS COUSAS NOTAVEIS QUE SE ACHÃO ASSI NA TERRA COMO O MAR. [A00_0749 p. 35].

Veras, se he certo, o que te estou dizendo; Vamos seguindo, em quanto ha claridáde, $\mathrm{O}$ caminho da Aldea, em que vivendo Tapuyas, como nos, mas satisfeitos, A Ley de hum Deos conhecem; Seus Preceitos. HENRIQUE JOÃO WILKENS (1984) [1789], MUHURAIDA OU O TRIUMFO DA FÉ (1785) / MANUSCRITO E TRANSCRIÇÃO DIPLOMÁTICA. IMPRESSÃO ESPELHADA. DIRCEU LINDOSO - CANTO TERCEIRO. [A00_2333 p. 121].

Figurado

Conhecimento, ciência.

[...] foy bautizado na Parochial Igreja do Corpo Santo, e logo no oriente da luz da razão deo mostras da grande claridade de juizo, de que o ceo o dotara, [...].FREI DOMINGOS DE LORETO COUTO (1904) [1757], LIVRO QUARTO - PERNAMBUCO ILLUSTRADO COM VIRTUDES / CAP. XIII-VENERÁVEIS,MEMORIAS DE MUITOS NATURAES DE PERNAMBUCO, QUE NA SAGRADA RELIGIÃO DA COMPANHIA DE JESUS FLORECERÃO EM VIRTUDE E DOUTRINA. N. 79. [A00_0667 p. 286]. 


\section{Expressão sintagmática}

Dote de claridade.

Qualidade sobrenatural que emanando da alma bem-aventurada, faz o corpo glorioso diáfano, e transparente como cristal. Além do dote de qualidade há os de impassibilidade, agilidade e sutileza.

[...] porque á Magdalena se representou como hortelão, e aos de Ammaús, como peregrino. Só no monte Thabor foi visto com o dote de claridade no rosto resplandecente como o sol, o nos vestidos tão alvos como a neve [...]. PADRE ANTONIO VIEIRA (1951) [1658], SERMÃO DA RESURREIÇÃO DE CHRISTO. [A00_0906 p. 187].

ver: dote

\section{$1^{a}$ datação}

[...] verdadeiro conhecymento e aRepemdimento delles porque com jso serya muito comsolado em sua alma e vsaryão com elle de muita claridade e lhe serya comcedida a mysericordia da Santa madre Jgreja [...]. JOÃO DE BOLÉS (1904) [1560], PROCESSO DE JOÃO DE BOLÉS E JUSTIFICAÇÃO REQUERIDA PELO MESMO (1560 - 1564). [A00_0827 p.269].

roubo s.m.

variante: robo

1. Furto acompanhado de força e violência.

E para fechar a porta á mayor parte dos robos, que se fazem nas compras de Diamantes aos Escravos; ordeno outrosim, que não haja venda alguma dentro da circumferencia do ditto Tejuco, [...]. CONDE DE GALVEAS (1964) [1733], DOCUMENTO H. PRIMEIRO BANDO DE 16 DE ABRIL DE 1733 PARA A CAPITAÇÃO SER DE VINTE CINCO MIL E SEISCENTOS ATHE O FIM DO ANNO E O MAIS QUE DELLE SE VÊ. [A00_1434 p.112].

2. Objeto resultante do furto.

[...] todo seu destrito assolasse tudo que visse com vida, e com prestimo, recolhendo todos os mantimentos do roubo, e todos os gados da campanha.

FREI DOMINGOS DO LORETO COUTO (1904) [1757], LIVRO SEGUNDO - PERNAMBUCO VENCIDO, E GLORIOSAMENTE 
RESTAURADO / CAP. IX - CONSTÂNCIA COM QUE CONTINUARÃO NA RESTAURAÇÃO DA PÁTRIA. N. 32 E N. 57. [A00_0628 p.113].

\section{$1^{\text {a }}$ datação}

Pois dos outros peccados que direi? Nam há paz, mas tudo odio, murmurações e detrações, roubos e rapinas, enganos e mentiras; não há obediencia nem se guarda hum soo mandamento de Deus e muyto menos os da Ygreja. P. MANUEL DA NÓBREGA (1956) [1559], CARTA DO P. MANUEL DA NÓBREGA A TOMÉ DE SOUSA ANTIGO GOVERNADOR DO BRASIL, BAÍA 5 DE JULHO 1559. [A00_0034 p.75].

\section{tabuleiro s.m.}

variantes: taboleiro, tabolleiro

1. Esplanada de terra ou areia.

[...] e está situada junto á margem oriental do rio Pacoti, e isto na distancia de 3 legoas da costa, sobre hum taboleiro de arêa que fica eminente a huma dilatada vargem coberta de huma especie de palmeiras chamadas carnahubas [...]. LUIZ DOS SANTOS VILHENA (1921) [1801], CARTA DÉCIMA NONA. [A00_0845 p. 685].

2. Utensílio feito geralmente de madeira com bordas, usado para transportar alimentos e bebidas.

[...] e constando-me juntamente, que nos corregos, e sitios, onde se minerão Diamantes, andão Negras com taboleiros, e outras vendendo Cachassas, o que em todas estas Minas he prohibido, [...]. CONDE DE GALVEAS (1964) [1733], DOCUMENTO I. BANDO DE 2 DE DEZEMBRO D 1733 PARA A CAPITAÇÃO SER DE $40 \$ 000$ REIS, E O MAIS SOBRE VENDAS, TRAFICANTES, E PESSOAS ESCANDALOZAS. [A00_1435 p. 114].

3. Planície na encosta de uma montanha.

[...] tornemos a América e Chapada grande, ou cobra enroscada. Dela nascem, ou saem todos, ou quase todos os rios da América, com a diferença, que os que nascem do primeiro taboleiro, ou Chapada grande, todos são rios grandes, [...]. PE. JOÃO DANIEL (1976) [1757], PARTE PRIMEIRA - CAP. $13^{\circ}$ NOTÍCIA DE ALGUNS LAGOS. [A00_1815 p. 75]. 
4. Espaço plano no topo da escada onde se inicia um outro lance ou patamar. Seu adro dá para a mesma rua, delineada por boa arquitetura com duas entradas que sobem a um tabuleiro da porta principal, indo ao Calvário da Cruz que nela se respeita, fabricado de cantaria. JOSÉ ALVARES DE OLIVEIRA (1981) [séc. XVIII], HISTÓRIA DO DISTRITO DO RIO DAS MORTES, SUA DESCRIÇÃO, DESCOBRIMENTO DAS SUAS MINAS, CASOS NELE ACONTECIDOS ENTRE PAULISTAS E EMBOABAS E CRIAÇÃO DAS SUAS VILAS. [A00_0395 p. 122].

5. Quadrado de madeira ou de marfim com xadrez usado para jogar xadrez, damas ou jogos de dados.

[...] porque haverão seis mezes pouco mais, ou menos deo elle testemunha ao dito Lucas Dantas hum tabolleiro de jogar tabulas, para o concertar, e porque se demorou quatro dias sem o dar concertado, [...]. desconhecido (1931) [1798], BAHIA -DEVASSAS E SEQUESTROS. [A00_2265 p. 122].

6. Planície em degraus que fica ao redor das igrejas ou de edifícios.

Continúa pela retaguarda da igreja um melhor taboleiro de terra; serve de jogo de bola por ser infestado da saúba; corre ao longo d'elle pela parte do rio outro novo quartel, [...]. ALEXANDRE RODRIGUES FERREIRA [século XVII], 1. ${ }^{a}$ PARTE: ALTO RIO NEGRO - PARTICIPAÇÃO QUINTA: DE SANTA ISABEL A SÃO GABRIEL. [A00_2229 p. 159].

\section{$1^{a}$ datação}

A Sé da cidade do Salvador está situada com o rosto sobre o mar da Bahia, defronte do ancoradouro das náos, com um taboleiro defronte da porta principal, bem a pique sobre o desembarcadouro, d'onde tem grande vista. GABRIEL SOARES DE SOUSA (1938) [1587], DESCRIPÇÃO TOPOGRAPHICA DA BAHIA (PARTE SEGUNDA -TITULO 2). [A00_0178 p. 136].

subido adj.

variante: sobido

1. Que subiu, que se elevou.

Via-se o reino de Portugal subido a maior magestade na reputação, no imperio e nas riquezas, quando tudo viu sepultado nos campos da Africa, [...]. PEDRO 
TAQUES DE ALMEIDA PAES LEME (1980) [séc. XVIII], RENDONS. [A00_0076p. 249].

2. Caro, excessivo.

Antes quanto mais sobido for o preço haverá maior concurso, e resultará maior abundância e fartura; porque mais vale que hajam víveres embora que mais caros, [...]. PADRE JOÃO DANIEL (1976) [1757], QUINTA PARTE - DO TESOURO DESCUBERTO NO RIO MAXIMO AMAZONAS CONTÉM UM NOVO MÉTODO PARA A SUA AGRICULTURA; UTILÍSSIMA PRAXE PARA A SUA POVOAÇÃO, NAVEGAÇÃO, AUGMENTO, E COMÉRCIO, ASSIM DOS ÍNDIOS, COMO EUROPEOS - CAP. $11^{\circ}$ - MODO FÁCIL PARA SE PODEREM PRACTICAR OS MERCADOS NO RIO AMAZONAS. [A00_1961 p.374].

3. Eminente, elevado.

Porem, hoje, que a nossa America se vê tão subida de ponto, e de posto, vem adorar o Rei nascido com as demais, tão agradecida como confiada; [...]. PADRE ANTONIO VIEIRA (1951) [1641], SERMÃO DE DIA DE REIS. [A00_0913 p. 70].

4. Sublime, exaltado.

Mas como pôde a rainha nossa senhora, chegar a tão subido grau de prudencia no curso de tão poucos annos? A prudencia é filha do tempo e da razão: da razão pelo discurso, do tempo pela experiencia. PADRE ANTONIO VIEIRA (1951) [1684], PALAVRA DE DEUS EMPENHADA NO SERMÃO DAS EXEQUIAS DA RAINHA D. MARIA FRANCISCA ISABEL DE SABOYA. [A00_1043 p. 369].

5. Fino, perfeito.

O ouro se poem na ley de vinte e dous quilates, que tem todas as moedas do Reyno. Paga-se às partes pelo que toca, por ser mais puro, e subido, e ter vinte e dous, vinte e tres, e algum vinte e quatro quilates, [...]. SEBASTIÃO DA ROCHA PITTA (1878) [1730], LIVRO DECIMO. [A00_0576 p. 416].

6. Vivo, penetrante. Usa-se no feminino referindo-se à cor.

Ha outros passarinhos pequenos todos vestidos de azul, côr muito subida, aos quaes os indios chamam sayubui, que tem o bico preto, e criam em arvores, e mantem-se dos bichinhos da terra. GABRIEL SOARES DE SOUSA (1938) [1587], DAS AVES (PARTE SEGUNDA - TITULO 10). [A00_0186 p.274]. 


\section{$1^{\mathrm{a}}$ datação}

E todos, assim uns como outros, fazem suas lavouras e granjearias com escravos de Guiné, que para êsse efeito compram por subido preço. AMBRÓSIO FERNANDES BRANDÃO (1966) [1618], DIÁLOGO PRIMEIRO. [A00_1581 p. 10].

$\operatorname{melado}^{1}$ adj.

Untado com mel.

Para enrolar o Tabaco, dobraõ a corda já curada, \& melada, de comprimento de tres palmos, nobre huPa entaca, naõ muito gronna, \& leve, que nas extremidades tem quatro taboinhas em cruz: [...]. ANDRÉ JOÃO ANTONIL (1711) [1711], SEGUNDA PARTE - NA LAVRA DO TABACO. [A00_2579 p. 113].

\section{$1^{\text {a }}$ datação}

BRANDÔNIO A ordem é esta: depois do açúcar limpo e melado nas caldeiras, se passa a umas tachas também de cobre, aonde à fôrça de fogo o fazem pôr no ponto necessário para haver de coalhar [...]. AMBRÓSIO FERNANDES BRANDÃO (1966) [1618], DIÁLOGO TERCEIRO - EM QUE SE TRATA DAS MERCANCIAS DO AÇÚCAR, PAU, ALGODÃO, MADEIRA. [A00_1583 p. 85].

$\operatorname{melado}^{2}$ s.m.

variante: mellado

Calda grossa e escura feita de cana-de-açúcar que depois de cozida se apura para ir às tachas.

[...] porq. o tenpo me não da lugar p. ${ }^{a}$ regallos, as seias paço com hum prato de milho cozido em agoa com huma colher de mellado, cujo prato lhe dão qua de quangiqua [...]. FRANCISCO DA CRUZ (1973) [1726], CARTAS REMETIDAS PARA LISBOA-MINAS GERAIS. [A00_0437 p. 288].

[...] eu fue servido concedervos por requerimento q. me havieis feito, de vos permitir q. pudeceis impor de trebuto de cada Barril de Agoardente ou Mellado, a meya pataca de ouro, [...]. CONDE DOM PEDRO DE ALMEIDA (1955-1957) [1718], NO GOVÊRNO DO CONDE DE ASSUMAR. [A00_0766 p. 64]. 
ver: tacha

holanda, s.f.

variantes: hollanda, ollanda, olanda.

Tecido de linho fino usado para vestuário, fabricado na Holanda, de onde o seu nome.

Que entendo, que inda estava o lacre quente, Quando eu já sobre os membros fatigados Cuidadoso estendia a grossa manta. Não cuides, Doroteu, que brandas penas Me formam o colchão macio, e fofo: Não cuides, que é de paina a minha fronha, E que tenho lençóis de fina Holanda [...]. TOMÁS ANTÔNIO GONZAGA (2000) [1763], CARTA 2a [A00_1214 p. 65].

[...] \& por fóra, entará a Sagrada Hontia, \& as praticulas que parecerem bantantes, que haõ de ner renovadas ao menos cada quinze dias, em corporaes de linho fino, ou de ollanda muyto limpos. (1920, OBRA IMPRESSA / 2006, REPRODUÇÃO DIGITAL) [1767], No 590 - DATA E SESMARIA DE MANOEL LOPES CABREIRA, DE TRES LEGUAS DE TERRA NO RIO SALGADO, CONCEDIDA PELO GOVERNADOR TENENTE CORONEL ANTONIO JOZÊ VICTORIANO BORGES DA FONSECA, EM 12 DE MAIO DE 1767. [A00_2466 p. 46].

[...] por troco das roupas e mantimentos de qP o Reino padece falta, e como estas ja naõ poderia escuzar, permanecendo no luxo das olandas, Cambraes, londres, galas; seP tornar ao parco uso dos antigos (que ja sera impossiuel) contentandose de seu linho beiraõ e Lam d'Alemtejo. desconhecido (1958) [1607], MEMORIAL DO ESTADO DO BRASIL PARA SUA MAJESTADE. CONTÉM MINUCIOSA INFORMAÇÃO SÔBRE OS DANOS DA NAVEGAÇÃO DO BRASIL, REMÉDIO ÚTIL E SUAS CONVENIÊNCIAS - A ORGANIZAÇÃO DE FROTAS COMBOIADAS - 1627 (131]. [A00_2113 p. 317].

\section{$1^{\text {a }}$ datação}

[...] poderáõ trazer roupetas, \& caIçoePs de neda, conforme a nua ponnibilidade, mas de côr preta, parda, ou roxa, nem guarniçoens, pannamanes, galoess, enpeguilhas, alamares de ouro, prata, dourados, ou prateados, \& os giboePs poderáõ ner das menmas cores, ou brancos de linho, ou hollanda. [...]. - (1920, OBRA IMPRESSA / 2006, REPRODUÇÃO 
DIGITAL) [1767], N 590 - DATA E SESMARIA DE MANOEL LOPES CABREIRA, DE TRES LEGUAS DE TERRA NO RIO SALGADO, CONCEDIDA PELO GOVERNADOR TENENTE CORONEL ANTONIO JOZÊ VICTORIANO BORGES DA FONSECA, EM 12 DE MAIO DE 1767. [A00_2466 p. 184].

4. Considerações finais

Tem-se, portanto, em linhas gerais, como está sendo construído o dicionário Histórico do Português do Brasil:- séculos XVI, XVII e XVIII que deverá registrar, aproximadamente, 10 mil verbetes quando de seu término.

Vem a calhar, aqui, como fecho a este texto, o excerto abaixo extraído de $A$ Verdade dos Dicionários de H. Weinrich (1979: 314):

Fazer um dicionário é um assunto sumamente laborioso que requer, além de capacidades científicas tão espetaculares como agudeza de espírito, fantasia, coerência e juízo crítico, muitas virtudes discretas, aparentadas com as dos artífices, como paciência, assiduidade, constância, precisão nos pormenores e por último mas não em ínfimo lugar - uma grande paixão de colecionador.

Referências bibliográficas

BIDERMAN, M. T. de C. 1984. A ciência da lexicografia. Alfa 28. 1-26. Supl.

CAMPOS SOUTO, M.; PEREZ PASCUAL, José Ignácio. 2003. El diccionario y otros productos lexicográficos. In: MEDINA GUERRA, A. M. (coord.). Lexicografía española. Madrid: Ariel. p.53-78

DUBOIS, J.; DUBOIS, C. 1971. Introduction à la lexicographie: le dictionnaire. Paris: Larousse. HAENSCH, G. 1982. Tipologia de las obras lexicográficas. In: HAENSCH, G.; WOLF L.; ETTINGER, S.; WERNER, R. La Lexicografía: de la lingüística teórica a la lexicografía práctica. Madrid: Editorial Gredos. p. 95-187.

IMBS, P. 1960. Au seuil de la lexicographie. Cabiers de Lexicologie 2. 3-17.

MATORÉ, G. 1968. Histoire des dictionnaires français. Paris: Larousse.

PORTO DAPENA, J.-Á. 2002. Manual de técnica lexicográfica. Madrid: Arco Libros.

WEINRICH, H. 1979. A verdade dos dicionários: problemas de lexicologia e lexicografia. Tradução de Mario Vilela. Porto: Livraria Civilização. p. 314-35.

Obras de referência

AULETE, F. J. C. 1881. Diccionario contemporâneo da língua portugueza. Lisboa: Imprensa Nacional. $2 \mathrm{v}$. 
BLUTEAU, R. 1712-1728. Vocabulário portuguez e latino. Coimbra: Collegio das Artes da Companhia de Jesus. $10 \mathrm{v}$.

CUNHA, A. G. 1996. Dicionário etimológico nova fronteira da Lingua Portuguesa. 2 ed. Rio de Janeiro: Nova Fronteira.

FERREIRA, A. B. de H. 2001. Novo dicionário Aurélio de língua portuguesa. 2ed. rev. ampl. Rio de Janeiro: Nova Fronteira.

FIGUEIREDO, C. 1925. Novo diccionario da lingua portuguesa. Lisboa: Portugal-Brasil: Sociedade Arthur Brandão. 2 v.

FREIRE, L. 1939-1943. Grande e novíssimo dicionário da lingua portuguesa. Rio de Janeiro: A Noite. $5 \mathrm{v}$.

HOUAISS, A.; VILLAR, M. de S.; FRANCO, MELLO, F. M. de. 2001. Dicionário Honaiss de lingua portuguesa. Rio de Janeiro: Objetiva.

LITTRÉ, É. 1875-1877. Dictionnaire de la langue française. Paris: Hachette. 4 v.

MACHAD0, J. P. 1967. Dicionário etimológico da lingua portuguesa: com a mais antiga documentação escrita e conhecida de muitos dos vocábulos estudados. 2 ed. Lisboa: Editorial Confluência.

NASCENTES, A. 1932. Dicionário etimológico da lingua portuguesa. Rio de Janeiro: Francisco Alves.

1961-1967. Dicionário da lingua portuguesa. Rio de Janeiro: Departamento de Imprensa Nacional. $194 \mathrm{v}$.

PINTO, L. M. da S. 1832. Diccionario da língua brasileira. Ouro Preto: Typographia Silva.

SILVA, A. de. M. s.d. Diccionario da lingua portugueza. 9 ed. Lisboa: Editora Empreza Litteraria Fluminense de Santos, Vieira \& Commandita. 2 v.

1813. Diccionario da lingua portugueza. Lisboa: Typographia Lacerdina. 2 v.

. 1789. Diccionario da lingua portugueza. Lisboa: Officina de Simão Thaddeo Ferreira. 2

1949-1959. Grande dicionário da língua portuguesa. 10 ed. Organização de Augusto

Moreno, Cardoso Junior e José Pedro Machado. Lisboa: Editorial Confluência. 12 v.

VIEIRA, D. Frei. 1871-1874. Grande diccionario portuguez ou thesouro da lingua portuguesa. Porto:

Editores Ernesto Chardron e Bartholomeu H. de Moraes. 5 v. 